\title{
Chemoinformatic-guided engineering of polyketide synthases
}

Amin Zargar, ${ }^{1,2,4}$ Ravi Lal $^{1,2}$, Luis Valencia ${ }^{1,2}$, Jessica Wang ${ }^{1,2}$, Tyler Backman ${ }^{1,2}$, Pablo Cruz-

Morales $^{1,2}$, Ankita Kothari ${ }^{1-2}$, Miranda Werts ${ }^{1,2}$, Andrew R. Wong ${ }^{1,2}$, Constance B. Bailey ${ }^{1,2,4}$,

Arthur Loubat $^{1,2}$, Yuzhong Liu ${ }^{1,2}$, Veronica Benites ${ }^{1,2,3}$, Samantha Chang ${ }^{1,2}$, Amanda C.

Hernández ${ }^{1,2}$, Jesus F. Barajas ${ }^{1-3}$, Mitchell G. Thompson ${ }^{1,2}$, Carolina Barcelos ${ }^{1,2}$, Rasha

Anayah $^{1,2}$, Hector Garcia Martin ${ }^{1-3,9}$, Aindrila Mukhopadhyay ${ }^{1,2}$, Edward Baidoo ${ }^{1,2,3}$, Leonard

Katz $^{1,4}$, Jay D. Keasling ${ }^{1-2,4-8}$

${ }^{1}$ Joint BioEnergy Institute, Lawrence Berkeley National Laboratory,

Emeryville, CA 94608, United States

${ }^{2}$ Biological Systems and Engineering, Lawrence Berkeley National Laboratory, Berkeley,

California, USA

${ }^{3}$ Department of Energy Agile BioFoundry, Emeryville, CA 94608, USA

${ }^{4}$ QB3 Institute, University of California-Berkeley, 5885 Hollis Street, 4th Floor, Emeryville, CA 94608, United States

${ }^{5}$ Department of Chemical \& Biomolecular Engineering, University of California, Berkeley, CA 94720, United States

${ }^{6}$ Department of Bioengineering, University of California, Berkeley, CA 94720, United States

${ }^{7}$ Novo Nordisk Foundation Center for Biosustainability, Technical University

Denmark, DK2970-Horsholm, Denmark

${ }^{8}$ Synthetic Biochemistry Center, Institute for Synthetic Biology, Shenzhen Institutes for

Advanced Technologies, Shenzhen, China

${ }^{9}$ BCAM, Basque Center for Applied Mathematics, 48009 Bilbao, Spain 
bioRxiv preprint doi: https://doi.org/10.1101/805671; this version posted October 16, 2019. The copyright holder for this preprint (which was not certified by peer review) is the author/funder, who has granted bioRxiv a license to display the preprint in perpetuity. It is made available under aCC-BY-ND 4.0 International license.

\section{${ }^{*}$ Corresponding author}

Jay D. Keasling

jdkeasling@lbl.gov 


\section{Abstract}

2 Polyketide synthase (PKS) engineering is an attractive method to generate new molecules such

3 as commodity, fine and specialty chemicals. A central challenge in PKS design is replacing a

4 partially reductive module with a fully reductive module through a reductive loop exchange,

5 thereby generating a saturated $\beta$-carbon. In this work, we sought to establish an engineering

6 strategy for reductive loop exchanges based on chemoinformatics, a field traditionally used in

7 drug discovery. We first introduced a set of donor reductive loops of diverse genetic origin and

8 chemical substrate structures into the first extension module of the lipomycin PKS (LipPKS1).

9 These results demonstrated that chemical similarity between the substrate of the donor loops

10 and recipient LipPKS1 correlated with product titers. Consequently, we identified donor loops

11 with substrates chemically similar to LipPKS1 for further reductive loop exchanges, and we

12 observed a statistically significant correlation with production. Reductive loops with the highest

13 chemical similarity resulted in production of branched, short-chain fatty acids reaching a titer of

$14165 \mathrm{mg} / \mathrm{L}$ in Streptomyces albus J1074. Collectively, our work formulizes a new

15 chemoinformatic paradigm for de novo PKS biosynthesis which may accelerate the production

16 of valuable bioproducts. 


\section{Intro}

As the architecture of Type I PKSs determines molecular structure, rational reprogramming of PKS enzymes for the biosynthesis of new polyketides has been a major research thrust over the past three decades ${ }^{1-3}$ Like fatty acid synthases, PKSs extend the growing chain from the ketosynthase (KS) domain with a malonyl-CoA analog loaded onto the acyl carrier protein (ACP) by the acyltransferase (AT) domain through a decarboxylative Claisen condensation reaction. Unlike fatty acid synthases, which faithfully produce saturated fatty acids, PKSs have variability in $\beta$-carbonyl reduction, an attractive feature for molecular design. After chain extension, the $\beta$-carbonyl reduction state is determined by the reductive domains within the module, namely the ketoreductase $(\mathrm{KR})$, dehydratase $(\mathrm{DH})$, and enoylreductase $(\mathrm{ER})$, which generate the $\beta$-hydroxyl, $\alpha-\beta$ alkene, or saturated $\beta$-carbons respectively, when progressively combined. As the degree of $\beta$-carbon reduction is an important feature in molecular design, multiple studies have reported the engineering of a PKS module for various oxidation states of the $\beta$-carbon. ${ }^{4-8}$ However, design principles for introduction of reductive loop exchanges (i.e. KR-DH-ER domains) into partially reductive modules have not yet been developed. In this work, we compare bioinformatic and chemoinformatic approaches to guide reductive loop exchanges and formalize a new paradigm based on the chemical similarity of the substrate.

Chemoinformatics, an interdisciplinary field blending computational chemistry, molecular modeling and statistics, was initially developed for drug discovery through analysis of structure-activity relationships. ${ }^{9}$ Recently, we suggested that a chemoinformatic approach to PKS engineering could be valuable, particularly in reductive loop exchanges due to the dependence of the $\mathrm{KR}$ and $\mathrm{DH}$ domains on substrate size ${ }^{1}$. For example, due to a hydrophobic catalytic tunnel, ${ }^{10,11}$ acyl chain length had a critical influence on dehydration in both stand-alone $\mathrm{DH}^{12}$ and full PKS module studies. ${ }^{7}$ Moreover, a previous study of engineered reductive loop 
swaps resulted in a correlation between production and substrate size similarity of the donor reductive loops and the recipient module. ${ }^{13}$ Chemoinformatic methods such as atom pair (AP) similarity and maximum common substructure (MCS) similarity could be used to describe the substrate profiles for catalysis by these domains. AP similarity characterizes atom pairs (e.g. length of bond path, number of $\pi$ electrons), and MCS similarity is based on identifying the largest common substructure between two molecules. Both similarity methods can be translated to a Tanimoto coefficient with a range of 0 (least similar) to 1 (most similar) ${ }^{14}$ Based on the substrate-dependence of the reductive domains, we hypothesized that chemosimilarity between the substrates of donor and acceptor modules in reductive loop exchanges would correlate with production levels.

Bioinformatic studies of PKS evolution have guided engineering efforts in closely related biosynthetic gene clusters (BGCs). ${ }^{15,16}$ We therefore undertook a phylogenetic analysis of the reductive domain common to all reductive loops, the ketoreductase (KR). The KR not only reduces the $\beta$-keto group to a $\beta$-hydroxyl, but also sets the stereochemistry of the $\beta$-group and, if a branched extender is used, sets the $\square$-carbon stereochemistry resulting in subtypes $A 1, A 2$, B1, B2 (Figure 1A). We generated a phylogenetic tree of every manually curated ketoreductase and ketosynthase in ClusterCAD, a database for Type I PKSs, totaling 72 biosynthetic gene clusters (BGCs) and 1077 modules (Figure 1B). ${ }^{17}$ This evolutionary reconstruction revealed that KR-only B1 subtypes split from a common ancestor of fatty acid synthases and iterative PKSs ${ }^{18}$ As in previous investigations, we found that KR-only B1 subtypes later resulted in the addition of $\mathrm{DH}$ and $\mathrm{DH} / \mathrm{ER}$ domains, ${ }^{19}$ likely through recombination. ${ }^{20}$ We extend this finding to note that the KR-only B1 subtype branch diverged to produce the other KR-only subtypes (i.e.

A1, A2 and B2) (Figure 1B, Supplementary Figure 1). While KR domains cluster by the presence of a $\mathrm{DH}$ or $\mathrm{DH}-\mathrm{ER}$ domains, $\mathrm{KS}$ domains do not phylogenetically cluster by the type of reductive domains active in the module (Supplementary Figure 2). ${ }^{19}$ The KRs generally grouped by their product types, and this suggests a link between their evolution and product 
specificity, analogous to the evolution of KS domains of cis-AT ${ }^{19}$ and trans-AT PKS modules ${ }^{21,22}$ towards substrate specificity. As KRs from KR-DH-ER modules evolved distinctly from KR-only modules, we hypothesized that the KR phylogenetic distance between the donor loops and acceptor module in reductive loop exchanges was unlikely to correlate with production levels.

\section{Results and Discussion}

To compare the importance of chemical similarity and phylogenetic distance in reductive loop exchanges, we swapped diverse reductive loops into the first module of the lipomycin PKS as the acceptor module. In our previous work, we introduced a heterologous thioesterase from 6-deoxyerythronolide (DEBS) into the C-terminus of the first module of the lipomycin PKS (denoted Lip1TE); the resulting truncated PKS produced a $\beta$-hydroxy acid. ${ }^{23}$ In this work, our experimental design was based on introducing full reductive loops using conserved residues as exchange sites (denoted "A", "B" and "C") in Lip1TE (Scheme 1). ${ }^{7}$ We selected these conserved residues based on our work in reductive loop exchanges in the first module of borreledin. ${ }^{7}$ To evaluate the effects of genetic and chemical similarity, we identified five donor reductive loops (IdmO, indanomycin, S. antibioticus; SpnB, spinosyn, S. spinosa; AurB, aureothin, S. aureofaciens; NanA2, nanchangamycin, S. nanchangensis; MAS, mycoserosic acid, $M$. marinum) to swap into Lip1TE. A pairwise comparison of phylogenetic distance as well as direct sequence identity illustrates that the KR domain of the three donor reductive loops IdmO, SpnB, and AurB are the most similar to the KR in LipPKS1 (Figure 2A). A similar trend also holds in the analysis of the KS domain (Supplementary Figure 3). In contrast, the NanA2 substrate is the most chemically similar to LipPKS1, followed by SpnB, based on AP similarity (Figure 2B) and MCS similarity (data not shown). With the introduction of a reductive loop swap, the chimeric enzymes would programmatically produce 2,4-dimethyl pentanoic acid. As in vitro PKS studies have shown divergence from in vivo results ${ }^{24,25}$ due to underestimation of factors including limiting substrate, crowding, and solubility, ${ }^{26}$ we cloned ten chimeric modules into an 

aCC-BY-ND 4.0 International license.

E. coli -Streptomyces albus shuttle vector and conjugated it into Streptomyces albus J1074 (Table S1). ${ }^{27}$ Following ten-day production runs in a rich medium, cultures of Streptomyces albus harboring each of the constructs were harvested and the supernatants were analyzed with LC-MS for product levels. of the desired product and the AP and MCS chemosimilarities of the donor and LipPKS1 module substrates (AP Spearman Rank Correlation of $R_{s}$ of 0.99 and $p<0.01 ; M C S R_{s}$ of 0.90 and $\mathrm{p}=\mathbf{0 . 0 4}$ ) (Figure $\mathbf{2 C}$ ). On the other hand, no correlation between product titer and phylogenetic distance or sequence similarity of the KS or KR domains was found. Based on our bioinformatic analysis, this was not surprising as the lipomycin $\mathrm{KR}$ is an A2-type, evolving separately from a KR with a full reductive loop. This trend held with either junction A or B, although generally junction B chimeras resulted in higher levels of production, as demonstrated in a previous study of reductive loop exchanges. ${ }^{7}$ We found that substituting the donor loop most chemically similar to LipPKS1, NanA2, resulted in the highest titers of the desired product, 2,4-dimethyl pentanoic acid, reaching $165 \mathrm{mg} / \mathrm{L}$. Low titers of the intermediate 2,5-dimethyl-3hydroxypentanoic acid were produced, which we hypothesize is due to a comparatively lower rate of turnover at the energetically intensive $\mathrm{DH}$ domain, ${ }^{28}$ resulting in premature cleavage of the stalled product by hydration or by the thioesterase. As in our previous study of in vitro production of adipic acid, we did not detect alkene or keto acid stalled products ${ }^{7}$. This is not surprising as non-functional KRs produce short chain $\beta$-keto acids that spontaneously decarboxylate to form ketones, whereas ERs have been generally shown to rapidly reduce trans double bonds.

Based on these results, we took a chemoinformatic approach to further test our hypothesis that chemosimilarity is a critical factor in PKS engineering. We searched the ClusterCAD ${ }^{17}$ database for PKS modules with full reductive loops and substrates of high chemical similiarity to that of the KR of LipPKS1. The closest matches identified were PKS 
modules from laidlomycin and monensin, which used the same substrate as nanchangamycin.

121 (Figure 3A). As junction B resulted in levels of production superior to junction A, we cloned the 122 reductive loops of LaidSII and MonA2 into junction B of lipomycin. The chimeric PKSs

123 containing reductive loops with substrates of similar chemical structure (NanA2, LaidSII, and

124 MonA2) produced higher titers of the desired fully reduced product than less chemically similar

125 reductive loops. We determined a Spearman rank correlation between AP Tanimoto

126 chemosimilarity and production to have an $R_{s}$ of 0.89 and a $p$-value of less than 0.01 compared

127 to a correlation of $R_{s}$ of 0.85 and $p$ value of 0.01 for MCS chemosimilarity. With divergent

128 methods of chemical similarity calculations (AP and MCS), we found a statistically significant

129 correlation between substrate similarity and product titer.

130 In this work, we have undertaken a bioinformatic and chemoinformatic analysis of

131 reductive loop exchanges. Through a phylogenetic reconstruction, we suggested that the

132 evolutionary history of KR-only modules does not reveal useful information for predicting

133 production rates in reductive loop swaps; in fact, phylogenetic distance and sequence similarity

134 between donor KRs of full reductive loops and recipient KRs of partial loops did not correlate to

135 production. Highlighting previous literature regarding the importance of substrate size in

136 reductive domains, we hypothesized that the field of chemoinformatics, traditionally used to

137 study structure-activity relationships in drug discovery, could be applied to PKS engineering to

138 better predict production results. Using different reductive loops of varying phylogenetic and

139 chemical similarity, we determined that chemosimilarity had a strong correlation with product

140 titers. Based on these findings, we selected two more reductive loops with the most chemically

141 similar substrates to LipPKS1 and found higher levels of production. The analysis of our results

142 and previous experiments formalize a new paradigm in PKS engineering based on the

143 chemosimilarity of the substrate between the donor and recipient modules. These design

144 principles may fast-track the combinatorial approach currently taken for de novo biosynthesis

145 and develop a framework to more rapidly produce valuable biochemicals. 
bioRxiv preprint doi: https://doi.org/10.1101/805671; this version posted October 16, 2019. The copyright holder for this preprint (which was not certified by peer review) is the author/funder, who has granted bioRxiv a license to display the preprint in perpetuity. It is made available under aCC-BY-ND 4.0 International license.

146

\section{Acknowledgements}

148 This work was funded by the DOE Joint BioEnergy Institute (http://www.jbei.org) supported by

149 the U.S. Department of Energy, Office of Science, Office of Biological and Environmental

150 Research, through contract DE-AC02-05CH11231 between Lawrence Berkeley National

151 Laboratory and the U.S. Department of Energy, the National Institute of Health Awards

152 F32GM125179, F32GM125166 and the Agile Biofoundry sponsored by the U.S. DOE Office of

153 Energy Efficiency and Renewable Energy, Bioenergy Technologies and Vehicle Technologies

154 Offices, under Contract DEAC02-05CH11231 between DOE and Lawrence Berkeley National

155 Laboratory. H.G.M. was also supported by the Basque Government through the BERC 2018-

1562021 program and by Spanish Ministry of Economy and Competitiveness MINECO: BCAM

157 Severo Ochoa excellence accreditation SEV-2017- 0718.

158 Competing Financial Interest

159 J.D.K. has a financial interest in Amyris, Lygos, Demetrix, Napigen, Maple Bio, Berkeley

160 Brewing Sciences, Ansa Biotech and Apertor Labs.

161

162

163 
(1) Barajas, J. F.; Blake-Hedges, J. M.; Bailey, C. B.; Curran, S.; Keasling, J. D. Synthetic and Systems Biotechnology 2017, 2, 147-166.

168 (2) Khosla, C.; Herschlag, D.; Cane, D. E.; Walsh, C. T. Biochemistry 2014, 53, 2875-2883.

169

(3) Yuzawa, S.; Zargar, A.; Pang, B.; Katz, L.; Keasling, J. D. Commodity chemicals from engineered modular type I polyketide synthases.; 2018; Vol. 608, pp. 393-415.

171

(4) Reid, R.; Piagentini, M.; Rodriguez, E.; Ashley, G.; Viswanathan, N.; Carney, J.; Santi, D. V.; Hutchinson, C. R.; McDaniel, R. Biochemistry 2003, 42, 72-79.

(5) Keatinge-Clay, A. J. Mol. Biol. 2008, 384, 941-953.

(6) Kellenberger, L.; Galloway, I. S.; Sauter, G.; Böhm, G.; Hanefeld, U.; Cortés, J.; Staunton, J.; Leadlay, P. F. Chembiochem 2008, 9, 2740-2749.

(7) Hagen, A.; Poust, S.; Rond, T. de; Fortman, J. L.; Katz, L.; Petzold, C. J.; Keasling, J. D. ACS Synth. Biol. 2016, 5, 21-27.

(8) Gaisser, S.; Kellenberger, L.; Kaja, A. L.; Weston, A. J.; Lill, R. E.; Wirtz, G.; Kendrew, S. G.; Low, L.; Sheridan, R. M.; Wilkinson, B.; Galloway, I. S.; Stutzman-Engwall, K.; McArthur, H. A.; Staunton, J.; Leadlay, P. F. Org. Biomol. Chem. 2003, 1, $2840-2847$.

(9) Maldonado, A. G.; Doucet, J. P.; Petitjean, M.; Fan, B.-T. Mol Divers 2006, 10, 39-79.

(10) Herbst, D. A.; Jakob, R. P.; Zähringer, F.; Maier, T. Nature 2016, 531, 533-537.

(11) Barajas, J. F.; McAndrew, R. P.; Thompson, M. G.; Backman, T. W. H.; Pang, B.; de Rond, T.; Pereira, J. H.; Benites, V. T.; Martín, H. G.; Baidoo, E. E. K.; Hillson, N. J.; Adams, P. D.; Keasling, J. D. J. Ind. Microbiol. Biotechnol. 2019, 46, 1225-1235.

(12) Faille, A.; Gavalda, S.; Slama, N.; Lherbet, C.; Maveyraud, L.; Guillet, V.; Laval, F.; Quémard, A.; Mourey, L.; Pedelacq, J.-D. J. Mol. Biol. 2017, 429, 1554-1569.

(13) McDaniel, R.; Thamchaipenet, A.; Gustafsson, C.; Fu, H.; Betlach, M.; Ashley, G. Proc. Natl. Acad. Sci. USA 1999, 96, 1846-1851.

(14) Chen, X.; Reynolds, C. H. J Chem Inf Comput Sci 2002, 42, 1407-1414.

(15) Peng, H.; Ishida, K.; Sugimoto, Y.; Jenke-Kodama, H.; Hertweck, C. Nat. Commun. 2019, 10, 3918.

(16) Awakawa, T.; Fujioka, T.; Zhang, L.; Hoshino, S.; Hu, Z.; Hashimoto, J.; Kozone, I.; Ikeda, H.; Shin-Ya, K.; Liu, W.; Abe, I. Nat. Commun. 2018, 9, 3534.

(17) Eng, C. H.; Backman, T. W. H.; Bailey, C. B.; Magnan, C.; García Martín, H.; Katz, L.; Baldi, P.; Keasling, J. D. Nucleic Acids Res. 2018, 46, D509-D515.

(18) Keatinge-Clay, A. T. Chem. Biol. 2007, 14, 898-908.

(19) Zhang, L.; Hashimoto, T.; Qin, B.; Hashimoto, J.; Kozone, I.; Kawahara, T.; Okada, M.; Awakawa, T.; Ito, T.; Asakawa, Y.; Ueki, M.; Takahashi, S.; Osada, H.; Wakimoto, T.; Ikeda, H.; Shin-Ya, K.; Abe, I. Angew. Chem. Int. Ed. Engl. 2017, 56, 1740-1745.

(20) Jenke-Kodama, H.; Börner, T.; Dittmann, E. PLoS Comput. Biol. 2006, 2, e132.

(21) Nguyen, T.; Ishida, K.; Jenke-Kodama, H.; Dittmann, E.; Gurgui, C.; Hochmuth, T.; Taudien, S.; Platzer, M.; Hertweck, C.; Piel, J. Nat. Biotechnol. 2008, 26, 225-233.

(22) Vander Wood, D. A.; Keatinge-Clay, A. T. Proteins 2018, 86, 664-675.

(23) Yuzawa, S.; Eng, C. H.; Katz, L.; Keasling, J. D. Biochemistry 2013, 52, 3791-3793.

(24) Khosla, C.; Tang, Y.; Chen, A. Y.; Schnarr, N. A.; Cane, D. E. Annu. Rev. Biochem. 2007, 76, 195-221.

(25) Yan, J.; Hazzard, C.; Bonnett, S. A.; Reynolds, K. A. Biochemistry 2012, 51, 9333-9341.

(26) Zotter, A.; Bäuerle, F.; Dey, D.; Kiss, V.; Schreiber, G. J. Biol. Chem. 2017, 292, 1583815848.

(27) Phelan, R. M.; Sachs, D.; Petkiewicz, S. J.; Barajas, J. F.; Blake-Hedges, J. M.; Thompson, M. G.; Reider Apel, A.; Rasor, B. J.; Katz, L.; Keasling, J. D. ACS Synth. Biol. 2017, 6, 159-166. 
bioRxiv preprint doi: https://doi.org/10.1101/805671; this version posted October 16, 2019. The copyright holder for this preprint (which was not certified by peer review) is the author/funder, who has granted bioRxiv a license to display the preprint in perpetuity. It is made available under aCC-BY-ND 4.0 International license.

(28) Weber, A. L. J. Mol. Evol. 1991, 32, 93-100.

215

216

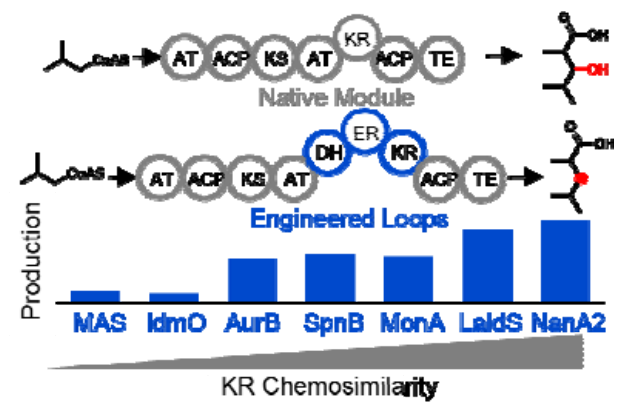

217

Graphical abstract

219

220

221 


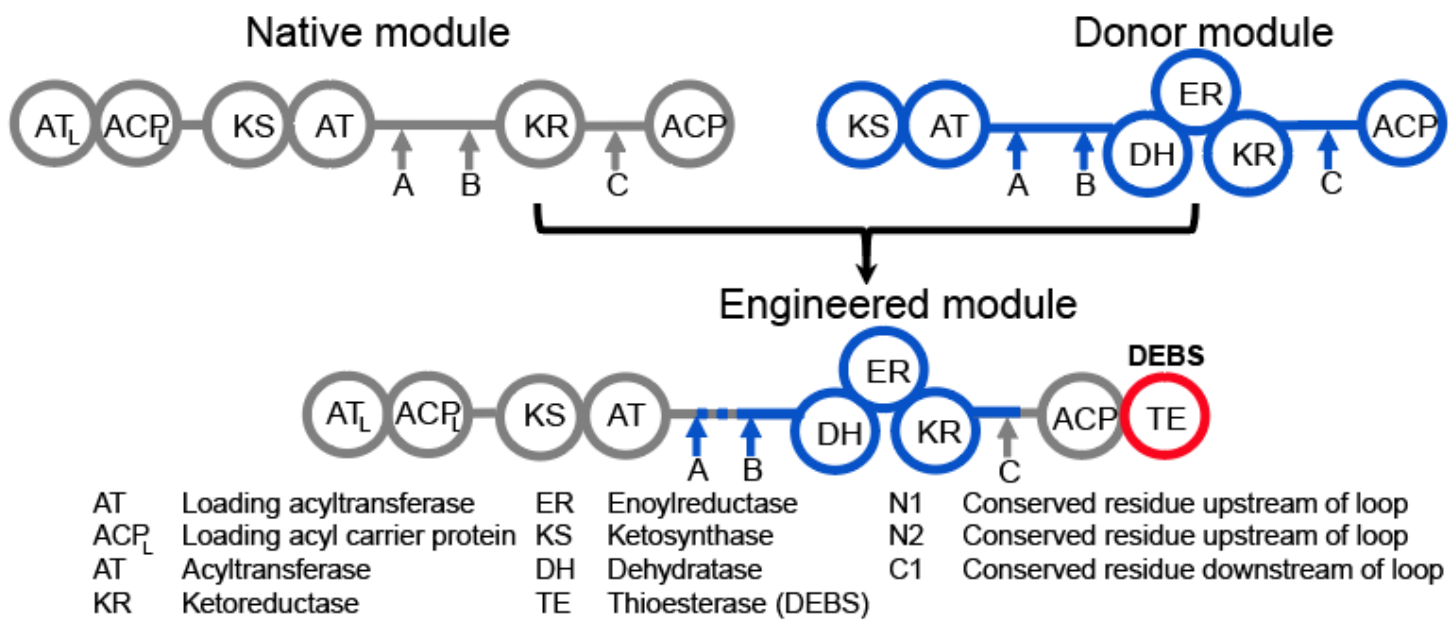

Scheme 1. Experimental design of PKS reductive loop swaps. Conserved residues are

225 identified through multiple sequence alignment surrounding the reductive domains ("A", "B" and

226 "C"). Donor reductive loops are inserted into the native lipomycin module, and the DEBS

227 thioesterase cleaves the product. 
bioRxiv preprint doi: https://doi.org/10.1101/805671; this version posted October 16, 2019. The copyright holder for this preprint (which was not certified by peer review) is the author/funder, who has granted bioRxiv a license to display the preprint in perpetuity. It is made available under aCC-BY-ND 4.0 International license.

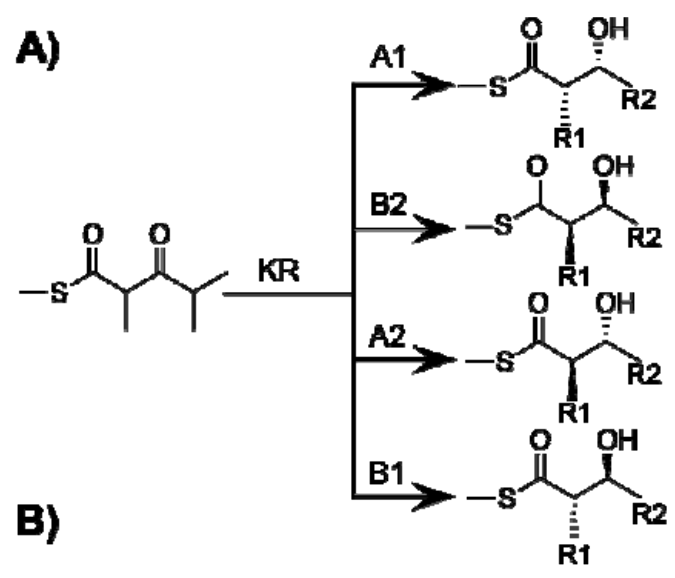

B-type KR (FAS \& iPKS)

B1-type KR with DH/ER

B1-type KR only

B2-type KR only

A1-type KR only

A2-type KR only
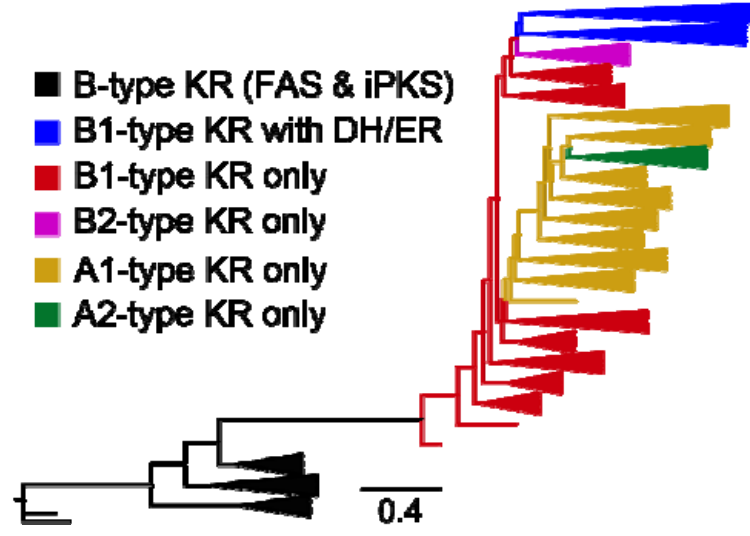

230 Figure 1. Bioinformatic analysis of reductive loop exchanges. A) KR subtypes determine the stereochemistry of the $\beta$-hydroxyl and $\square$-carbon B) Phylogenetic tree of the ketoreductase (KR)

232 domain of all manually curated KRs in ClusterCAD determined by ModelFinder in IQ-Tree. 
bioRxiv preprint doi: https://doi.org/10.1101/805671; this version posted October 16, 2019. The copyright holder for this preprint (which was not certified by peer review) is the author/funder, who has granted bioRxiv a license to display the preprint in perpetuity. It is made available under aCC-BY-ND 4.0 International license.

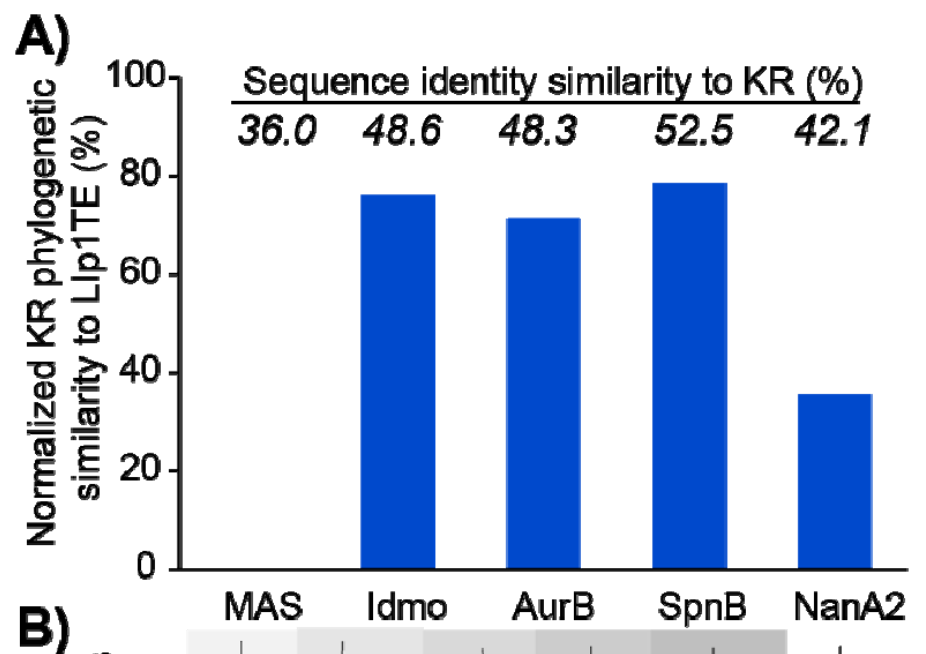

B)
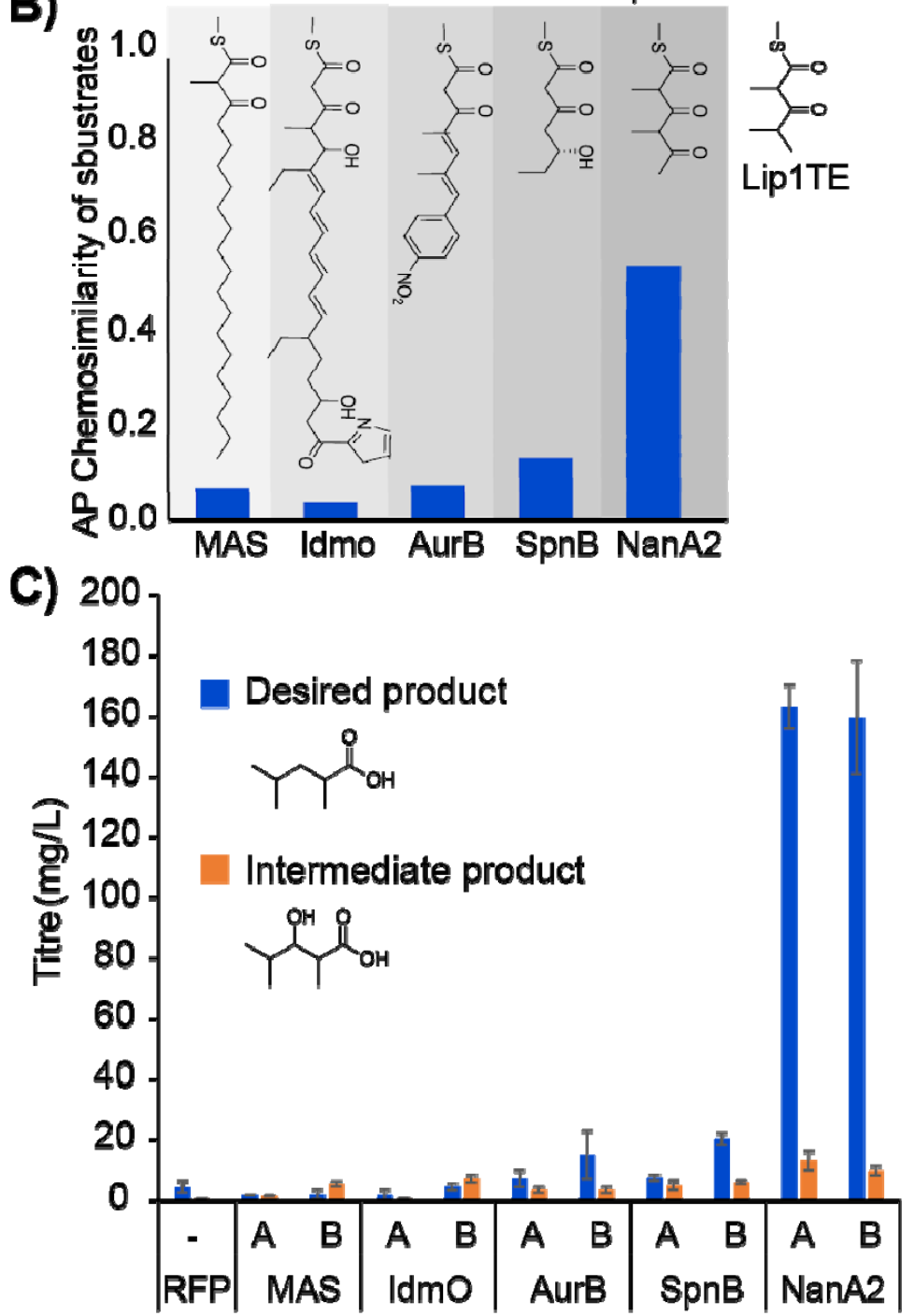

Donor Reductive Loop 
bioRxiv preprint doi: https://doi.org/10.1101/805671; this version posted October 16, 2019. The copyright holder for this preprint (which was not certified by peer review) is the author/funder, who has granted bioRxiv a license to display the preprint in perpetuity. It is made available under aCC-BY-ND 4.0 International license.

Figure 2. Phylogenetic and chemical similarity effects on reductive loop exchanges. A)

240 Phylogenetic similarity of the native Lip1 KR-only A2 subtype domain to each donor KR B1

241 subtype containing a $\mathrm{DH}$ and $\mathrm{ER}$, normalized to the most similar and least similar KR domain in

242 ClusterCad. The value above each bar denotes the sequence identity comparison. B) AP

243 chemical similarity between the native Lip1 KR domain and each of the donor KR domains in

244 this study. Chemical structures display native KR substrate in each module C) Polyketide

245 production of engineered PKSs at both junction "A" and junction "B". 
bioRxiv preprint doi: https://doi.org/10.1101/805671; this version posted October 16, 2019. The copyright holder for this preprint (which was not certified by peer review) is the author/funder, who has granted bioRxiv a license to display the preprint in perpetuity. It is made available under aCC-BY-ND 4.0 International license.

A)
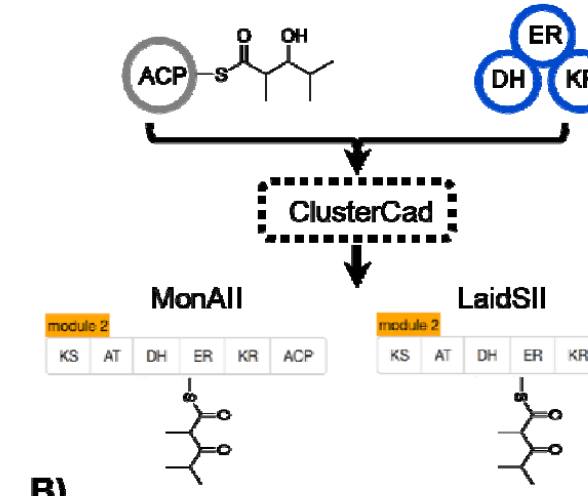

B)

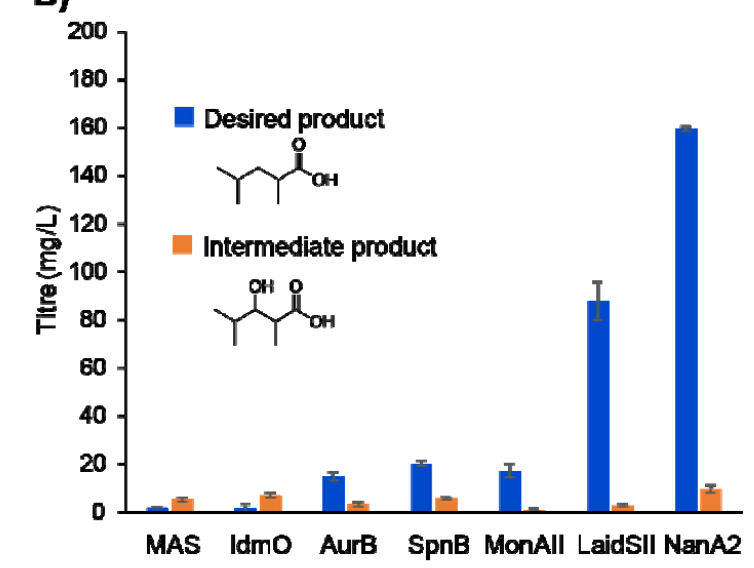

LaidSI

module 2

\begin{tabular}{l|l|l|l|l|l|}
\hline KS & AT & DH & ER & KR & ACP \\
\hline
\end{tabular}

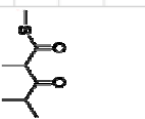

KR Chemosimilarity

Figure 3. A chemoinformatic approach to reductive loop exchanges. A) A search in

251 ClusterCad revealed the closest substrates to the first module of lipomycin containing a full

253 similarity to LipPKS1 (MonAll, LaidSII and NanA2) compared to donor loops with less KR

254 substrate similarity (MAS, IdmO, AurB, SpnB). 